\title{
Shifting mechanisms of elevational diversity and biomass patterns in soil invertebrates at treeline
}

\author{
Guorui Xu ${ }^{\text {a, b }}$, Yinghua Lin ${ }^{c}$, Shuang Zhang a, Yuxin Zhang a , Guixiang Li a , Keming Ma a, * \\ a State Key Laboratory of Urban and Regional Ecology, Research Center for Eco-Environmental Sciences, Chinese Academy of Sciences, Beijing 100085, China \\ ${ }^{\mathrm{b}}$ Key Laboratory of Tropical Forest Ecology, Xishuangbanna Tropical Botanical Garden, Chinese Academy of Sciences, Menglun, Yunnan 666303, China \\ ${ }^{\mathrm{c}}$ Institute of Wetland Research, Chinese Academy of Forestry, Beijing 100091, China
}

\section{A R T I C L E I N F O}

\section{Article history:}

Received 2 April 2017

Received in revised form

10 April 2017

Accepted 16 May 2017

Available online 7 June 2017

\section{Keywords:}

Elevational biodiversity patterns

Litter-dwelling invertebrates

Environmental correlates

Treeline

\begin{abstract}
A B S T R A C T
Ecologists and biogeographers have long been interested in the underlying mechanisms shaping the elevational patterns of biodiversity. However, most of these studies have been conducted aboveground. Although they deliver key ecosystem functions and services, the elevational diversity and biomass patterns of soil invertebrates, including a wide range of taxa, have been severely understudied, especially at treeline. To address this critical gap, we identified richness, abundance, and biomass patterns of soil invertebrates across an elevational gradient under below-treeline forest (from 1020 to 1770 asl) and above-treeline meadow (from 1790 to 2280 asl), respectively. We aimed to (1) identify the elevational patterns of richness, abundance, and biomass in soil invertebrates across the treeline; and (2) test whether these patterns break and the underlying mechanisms shift at the treeline. We found that both the diversity and biomass of litter-dwelling invertebrates showed hump-shaped patterns below the treeline and monotonically decreasing patterns above the treeline, respectively. Richness association of litter-dwelling invertebrates and herbaceous plants shifted from negative to positive at the treeline. For the soil-dwelling invertebrates, no elevational trends were detected in forest while the diversity decreased monotonically with elevation in meadow. In contrast to basal area and litter thickness in forest, temperature was most strongly related to the diversity of litter-dwelling invertebrates in meadow. We showed the breaks in elevational diversity patterns of soil invertebrates at the treeline, while elevational patterns of biomass did not change. Microclimate replaced productivity as the most important factor driving the diversity patterns of litter-dwelling invertebrates across the treeline with vegetation shifts induced by increasing elevation.
\end{abstract}

() 2017 Elsevier Ltd. All rights reserved.

\section{Introduction}

The underlying mechanisms shaping the elevational biodiversity patterns and the functioning of ecosystems have long been a central focus of ecologists and biogeographers (von Humboldt, 1849; Nogues-Bravo et al., 2008). Elevational patterns of diversity have been extensively researched across a wide array of taxonomic groups in aboveground organisms, including trees, mammals, birds, reptiles, insects, and amphibians (Rahbek, 2005). However, elevational diversity patterns of belowground organisms, which often represent decomposer subsystems, have been severely

\footnotetext{
* Corresponding author. Research Center for Eco-Environmental Sciences, Chinese Academy of Sciences, Beijing 100085, China.

E-mail address: mkm@rcees.ac.cn (K. Ma).
}

understudied (Loranger et al., 2001; Decaëns, 2010), especially those of soil invertebrates. In addition, compared with frequent assessments of species richness variation along elevational changes, elevational patterns for abundance and biomass have been studied less frequently.

Soil animals are essential mediators of multiple ecosystem functions and services, such as decomposition and nutrient cycling (Bardgett and van der Putten, 2014; Wall et al., 2015). Due to the laborious and time-consuming nature of sampling and identification (Decaëns, 2010), the few studies that have explored the elevational diversity of soil invertebrates have mostly concentrated on a focal group representing only a small part of the soil food web, and have generated mixed results. For example, no pattern in dipterans, decreasing pattern in termites, a hump-shaped pattern in beetle families richness (Collins, 1980), and even an increasing pattern in earthworm species richness (Gonzalez et al., 2007) have 
all been reported. To date, the elevational diversity patterns of soil invertebrates across a broad range of taxa remain largely unknown, especially when the vegetation shifts at treelines.

Treelines are among the most striking terrestrial vegetation boundaries separating largely contrasting ecosystems, where forests give way to lower-stature vegetation along a relatively short elevational gradient (Hoch and Korner, 2012). Overall productivity and shifts in biomass allocation between aboveground and belowground occur at treelines in a discontinuous way (Dawes et al., 2015). This characteristic may have knock-on effects on soil communities since above- and below-ground communities interact intimately (Wardle et al., 2004a). However, the effects of changing vegetation characteristics across treelines on the belowground subsystem are poorly understood.

Several mechanisms may govern the elevational patterns of soil invertebrate communities, including microclimatic, productivity, resource heterogeneity and soil property (Werenkraut and Ruggiero, 2014). Mircrolimatic hypotheses supposed that abiotic conditions shape the distributions of species, inducing that fewer species exist at high elevations due harsh conditions compare to low elevations (Grytnes and Mccain, 2007). Productivity hypotheses suggest that species distributions are constrained by total food resource availability (Evans et al., 2005; Hurlbert and Stegen, 2014). Heterogeneity hypotheses suggest that species distributions are controlled by the heterogeneity of differential resources quality (Werenkraut and Ruggiero, 2014). Finally, soil property hypotheses emphasize physical structure, heterogeneity of the soil habitat, and the availability of nutrients may affect the distribution of soil invertebrates (Nielsen et al., 2008). However, whether the mechanisms that drive elevational patterns of the decomposer assemblages shift under different vegetation types above and below the treeline remain unknown.

To address this critical knowledge gap, we chose an oakdominated forest transect (from 1020 to 1770 asl) that shifts to a meadow gradient (from 1790 to 2280 asl) up to the mountain top as a model system for investigating changes in soil invertebrate communities due to: (1) the strong contrast in terms of vegetation characteristics and plant functional groups between these habitats (Chen and Huang, 1997), and (2) the representative of both habitats across a large climatic gradient. We assessed richness, abundance, and biomass patterns of soil invertebrates across an elevation gradient under below-treeline forest and above-treeline meadow, respectively. We quantified litter-dwelling and soil-dwelling invertebrates separately, based on the different habitats in which they are mainly active. In particular, we tested (i) whether soil invertebrates show an elevational pattern in diversity (richness, abundance) and function (biomass), (ii) whether such a pattern, if it exists, breaks along with the succession from below-treeline forest to above-treeline meadow with increasing elevation, and (iii) whether the underlying mechanisms accounting for the variation in soil invertebrate communities shift at treeline.

\section{Materials and methods}

\subsection{Study system}

We selected the Beijing Forest Ecosystem Research Station of the Chinese Academy of Sciences $\left(40^{\circ} 00^{\prime \prime}-40^{\circ} 03^{\prime \prime} \mathrm{N}\right.$ and $115^{\circ} 26^{\prime \prime}$ $115^{\circ} 30^{\prime \prime} \mathrm{E}$ ), which is located on Dongling Mountain, about $100 \mathrm{~km}$ northwest of Beijing city, China, as the study area. The study area has a typical warm temperate continental monsoon climate with an average annual precipitation of $500-650 \mathrm{~mm}$ and a mean annual temperature of $5-10{ }^{\circ} \mathrm{C}$. The main soil type of this area is brown soil. The zonal vegetation of montane forest is highly heterogeneous and mainly includes oaks (Quercus spp.), mixed species (e.g.,
Tilia spp., Ulmus spp., Acer spp., Juglans mandshurica, and Fraxinus rhynchophylla, among others), birches (Betula spp.), and poplar (Populus davidiana). The forest also includes some conifers and shrubs (e.g., Larix principis-rupprechtii, Pinus tabuliformis, Prunus spp., Vitex negundo var. heterophylla, among others). The dominant species of subalpine meadow mainly include Saussurea purpurascens, Carex capillaris, and Iris ruthenicar.

In order to minimize heterogeneity among forest types, ten transects, all of which were dominated by $Q$. liaotungensis, were set up from the base to the top of every mountain western slope (the 10 transects each occupied a different elevational segment of the slopes), so together they formed a single montane forest elevational gradient (1020 m-1770 m). The lengths of the 10-m-wide transects ranged from $80 \mathrm{~m}$ to $180 \mathrm{~m}$. Each transect was divided into $10 \times 10 \mathrm{~m}$ plots (parallel to the slope), resulting in a total of 119 plots in the forest (one plot at one elevation). Above the treeline, 21 plots $(10 \mathrm{~m} \times 10 \mathrm{~m})$ with elevational intervals of approximately $20 \mathrm{~m}$ along the mountain western slope were also chosen to form an elevational gradient of subalpine meadow ranging from 1790 to $2280 \mathrm{~m}$ (which was close to the summit of the Dongling Mountain at $2303 \mathrm{~m}$ ). Thus, 140 plots across the elevational gradient of forest and subalpine meadow were selected for the study. Each plot was chosen with approximately the same aspect (western slope) and similar slopes (between $22^{\circ}$ and $48^{\circ}$ ), so as to ensure that climate serves as the major abiotic driver varying with elevation in this system. The elevation, latitude, and longitude of each plot were logged by a GPS unit. We enumerated tree and shrub diversity in the mountain forest transect plots. Herb diversity was investigated, and soil animals were sampled in three $1 \mathrm{~m} \times 1 \mathrm{~m}$ subplots of each plot both in the forest and in the meadow.

\subsection{Plant investigation}

In each plot, tree species $(\mathrm{DBH} \geq 2.0 \mathrm{~cm}$ ) were identified. The diameter at breast height (DBH), crown diameter, and height in the tree layer were measured for all individuals. Each species in the shrub layer was identified, and its coverage and height were measured. Three subplots $(1 \mathrm{~m} \times 1 \mathrm{~m})$ were mechanically selected (along the diagonal line of each plot) for investigating the abundance, coverage, and height of each herbaceous species.

\subsection{Soil animal collection and identification}

In August 2013, we applied two methods to sample soil animals in each subplot: (1) All the leaf litter in a $0.6 \times 0.6 \mathrm{~m}$ quadrat was collected from the $\mathrm{OL}$ horizon and the humus layer (OF and $\mathrm{OH}$ horizons) to extract litter-dwelling invertebrates. (2) Below the $\mathrm{OH}$ horizons, two soil cores with a diameter of $8 \mathrm{~cm}$ were sampled to extract soil-dwelling invertebrates. Each sample was placed in a cotton bag to ensure the activity of animals remained unaffected and was sealed to avoid exposure to light prior to extraction by heat in modified Tullgren extractors (Wallwork, 1976). Three litter samples in the same plot were mixed into one sample, and six soil cores were mixed into one sample. Most invertebrates were identified to the family or morphospecies level, aside from Mesostigmata and Prostigmata, which were identified at a suborder level. We recorded the litter-dwelling and soil-dwelling taxa as well as the abundance of invertebrates in each plot. We randomly measured the body length of 10 individuals or of all the individuals when less than 10 were found in one family or morphospecies in each sample. The dry weight $(\mathrm{mg})$ of each individual was calculated based on mass-length regressions (Xu et al., 2015), after which the average body mass of each family or morphospecies in each sample was obtained. Along with the abundance data, we determined the biomass of each family or morphospecies in each sample. The 
adults and larvae of beetles were analyzed as different morphospecies, considering the great difference in their morphology, food resource, and ecological roles in food webs.

\subsection{Environmental variables assessment}

\subsubsection{Microclimate}

Mean annual temperature (MAT), mean annual temperature range (TVAR), and sampling temperature (TINS) have been considered for thermal limitation of soil invertebrates, along with mean annual precipitation (MAP) for water limitation. MAT was obtained using iButton (1922L, supported by Maxim Integrated) for 2 years from May 2012 to May 2014, which were set to record temperatures automatically each hour. TVAR was estimated by subtracting the mean temperature during the coldest month from that of the hottest month. We measured the field temperature in each plot 6 times ( 2 times in each subplot $\times 3$ subplots in each plot) during soil invertebrate sampling. MAP was estimated using the local models adapted to predicting climatic indices on Dongling Mountain (Jiang et al., 1994), using altitude, latitude, and longitude as predictors.

\subsubsection{Productivity}

Considering that aboveground net primary productivity may be related with vegetation cover (Evans et al., 2005) or total plant biomass (Flombaum and Sala, 2007), woody cover (WOODYCOV) was estimated by the sum of the crown diameter of all woody plants in each plot. We also estimated the aboveground cover of herbs (HERBCOV). Basal area (BASEA) was used as a surrogate for woody biomass (Wardle et al., 2004b) as no species-specific allometries between size and biomass of all woody species were available. Litter thickness (LITTERTH) was also recorded at 6 random points in each plot to represent the total potential aboveground input.

\subsubsection{Resource heterogeneity}

We used the woody plant species richness (TSRICH) and herbaceous plant species richness (HERBRICH) to represent resource heterogeneity (Scherber et al., 2014) for soil invertebrates. We also assessed the quadratic items of TSRICH and HERBRICH to determine the potential complex relationships between the plants and soil invertebrates.

\subsubsection{Soil characteristics}

We assessed the physical characteristics of the soil, including soil moisture, bulk density (BULKDEN), soil conductivity, and soil texture (percentage of clay, silt, and sand) as well as soil chemical characteristics, including soil $\mathrm{pH}$, total nitrogen (TN) and phosphorus (TP) content, available nitrogen (AN) and phosphorus (AP) content, $\mathrm{C}: \mathrm{N}$ ratios and $\mathrm{C}: \mathrm{P}$ ratios (calculated based on the total carbon, nitrogen, and phosphorus content). Soil moisture and soil bulk density were determined by oven drying (in an aluminum box of $5 \mathrm{~cm}$ diameter), maintaining $105^{\circ} \mathrm{C}$ for $48 \mathrm{~h}$ until no further weight loss. Soil texture was determined using a Mastersizer 2000, Malvern. Soil pH and conductivity were measured using a Mettler Toledo FE20k pH meter and Lei-ci DDS 307A conductivity meter, using $10 \mathrm{~g}$ of soil and $25 \mathrm{ml}$ of distilled water. Total soil carbon (TC) and TN content were determined using an automated CHNSO analyzer (Elementar Vario EL III, Elementar Analysensysteme $\mathrm{GmbH}$, Hanau, GE). Total phosphorus content (AP) was measured through the Mo-Sb colorimetric method. Soil available nitrogen (AN) was measured using the alkaline hydrolysis diffusion method. Soil available phosphorus (AP) was measured using the Mo-Sb antispectrophotometry method.

\subsection{Statistical analyses}

\subsubsection{Estimation of elevational patterns in soil invertebrates and environmental variables}

Linear and quadratic regression models were used to determine the elevation diversity patterns in richness, abundance, and biomass of litter-dwelling and soil-dwelling invertebrates, respectively. General linear models (GLM) were applied to test the effect of elevation, vegetation and their interactions to determine whether it is necessary to evaluate the patterns separately at the treeline. Then, in order to determine whether breaks existed at treeline, we used pair-sampled $\mathrm{T}$ test to compare the residuals generated from the model fitted to the whole gradient and two separate gradients. Abundance and biomass data were $\log (x+1)$ transformed prior to analysis due to high variations. In addition, we also assessed the relationships between selected environmental variables and elevation in linear function and quadratic function, and opted for the superior model with the lower $p$ value.

\subsubsection{Association assessment of richness, abundance, and biomass of soil invertebrates with environmental variables}

Since our sampling was spatially exhaustive, spatial autoregression was taken into account by incorporating eigenvectorbased spatial filters calculated from the geographic distances in all the models using SAM 4.0 (Rangel et al., 2010). We tested the environmental hypotheses in forest and meadow elevational gradients separately by following three steps (Burnham and Anderson, 2002; Werenkraut and Ruggiero, 2014). First, we assessed each hypothesis independently in an exhaustive search. The model with the lowest AICc value based on the Akaike's information criterion was selected as the best single statistical model of the five hypotheses. Then, we selected the best predictors in each single hypothesis by conducting model averaging and calculating the relative importance $\left(w_{i}\right)$ of each environmental variable. Finally, the best composite model was generated by including all important environmental variables in the best single statistical model and variables with $w_{i}>0.9$ (Burnham and Anderson, 2002) in the other models.

We partitioned the richness, abundance, and biomass variances into four categories in order to quantify the relative contribution of environmental variables included in the final model and elevation: (1) the effect of environmental predictors alone; (2) the shared effect of environmental predictors and elevation; (3) the effect of elevation alone; and (4) unexplained variance (Werenkraut and Ruggiero, 2014).

\section{Results}

In total, 75,090 individuals (dwt 27,834.04 mg) subordinate to 132 families (morphospecies) in 29 orders belonging to 11 classes were sampled along the full gradient (Table 1). In the forest below the treeline, 70,292 individuals (dwt $26,583.59 \mathrm{mg}$ ) subordinate to 123 families (morphospecies) in 29 orders belonging to 11 classes were obtained, with Collembola, Parasitiformes, and Acariformes (35.83\%, $24.33 \%$, and $22.73 \%$ of the total abundance, respectively) as the dominant orders. In the meadow above the treeline, 4798 individuals (dwt $1250.45 \mathrm{mg}$ ) subordinate to 77 families (morphospecies) in 18 orders belonging to 8 classes were obtained, with Collembola, Diptera, Parasitiformes, and Acariformes (43.79\%, $17.92 \%, 16.97 \%$, and $10.63 \%$ of the total abundance, respectively) as the dominant orders (see Table S1 in Appendix S1 in Supporting Information for details). 
Table 1

Composition summary of soil invertebrates along the elevational gradient in Dongling Mountain.

\begin{tabular}{|c|c|c|c|c|c|c|}
\hline Habitat & Families & Orders & Classes & Individuals & Biomass (mg) & Dominant Orders (\% of abundance) \\
\hline Forest & & & & & & \\
\hline Litter-dwelling invertebrates & 123 & 29 & 11 & 62,019 & $25,659.62$ & Collembola (37.95\%) Parasitiformes (22.98\%) Acariformes (22.47\%) \\
\hline $\begin{array}{l}\text { Soil-dwelling invertebrates } \\
\text { Meadow }\end{array}$ & 65 & 19 & 9 & 8273 & 923.97 & Parasitiformes (34.50\%) Acariformes (24.68\%) Collembola (19.99\%) Diptera (11.12\%) \\
\hline Litter-dwelling invertebrates & 62 & 17 & 8 & 2750 & 946.78 & Collembola (56.69\%) Parasitiformes (14.62\%) Acariformes (11.42\%) \\
\hline Soil-dwelling invertebrates & 46 & 12 & 4 & 2048 & 303.67 & Diptera (31.45\%) Collembola (26.47\%) Parasitiformes (20.12\%) \\
\hline
\end{tabular}

LDI = litter-dwelling invertebrates; SDI = soil-dwelling invertebrates,

Dominant Orders were selected base on abundance data no less than $10 \%$ of the total individuals.

\subsection{Elevational patterns in richness, abundance, biomass, and associations}

The richness, abundance, and biomass of litter-dwelling invertebrates all followed hump-shaped patterns along the whole elevational gradient (Fig. 1a,b,c). The richness of soil-dwelling invertebrates also showed a hump-shaped pattern (Fig. 1d), but with a rather low interpretation $\left(R^{2}=4.77 \%\right)$. No elevational pattern existed either in abundance or in biomass of soil-dwelling invertebrates along the whole gradient (Fig. 1e and f). Elevation interacting with vegetation together affected all the patterns except the biomass of soil-dwelling invertebrates (Table 2). Furthermore, residuals in richness and abundance of soil invertebrates generated from model fittings of the whole gradient were significantly higher than those of two separate gradients below and above the treeline, while no significant difference was detected in biomass residuals (Table 3). Thus, it was necessary to separate the elevational patterns in the forest gradient and the meadow gradient.

For litter-dwelling invertebrates, the richness, abundance, and biomass all followed hump-shaped patterns along the forest elevational gradient and monotonically decreasing patterns (Fig. $1 \mathrm{a}-\mathrm{c}$ ) along the meadow elevational gradient. For soil-dwelling invertebrates, no elevational trends were detected in the forest (Fig. 1d-f), but in the meadow, aside from biomass (Fig. 1f), for which no pattern was found, both richness and abundance monotonically decreased (Fig. 1d and e) with elevation. The elevational trends were also supported by re-analyzing the dominant groups (Acari, Collembola) and rare groups (except Acari, Collembola) of soil invertebrates (Figs. S1a,b,c,d,e). In addition, we found humpshaped elevational richness pattern of rare groups in the forest gradient and also hump-shaped elevational abundance and biomass patterns of dominant groups in soil-dwelling invertebrates.

\subsection{Underlying environmental correlates determining elevational patterns of soil invertebrates}

In forest, both the richness and abundance of litter-dwelling invertebrates positively correlated with litter thickness and basal area as predicted by the productivity hypothesis (Table 4). Unexpectedly, the richness of litter-dwelling invertebrates showed a negative association (Table 4, Table S2 in Appendix S2) with herbaceous species richness, but shifted from positive to negative with increasing woody species richness (Fig. $2 \mathrm{a}-\mathrm{c}$ ). In addition to being most correlated with soil physical characteristics, the biomass of litter-dwelling invertebrates was also positively correlated with litter thickness and basal area (Table 4). The variations of soildwelling invertebrates in richness, abundance, and biomass were all best explained by soil characteristics hypotheses with different environmental predictors. For the richness of soil-dwelling invertebrates, $\mathrm{pH}$ and available phosphorus content account for the most part of its variance, while abundance was most explained by sand\% and biomass was most explained by soil moisture content and sand\%.

In the meadow, variances of litter-dwelling invertebrates in richness, abundance, and biomass were all best explained by temperature, as predicted by the microclimate hypothesis (Table 4, Table S3 in Appendix S2). The richness of soil invertebrates was also positively correlated with herbaceous species richness as predicted by the resource heterogeneity hypothesis (Table $4 \&$ Fig. 2). Soil characteristics best explained the abundance and biomass of soildwelling invertebrates, predicted by relatively different importance levels of physical (positively with silt\% and bulk density, respectively) and chemical variables (negatively correlated with total phosphorus content and positively with available phosphorous content, respectively). Details on the regressions of best explanatory variables along elevation can be seen in Table S4 in Appendix S3.

Variance partitioning showed that environmental predictors in the forest (Fig. 3a), independently of elevation (included in the final model), accounted most for the richness, abundance, and biomass among both litter-dwelling and soil-dwelling invertebrates. In the meadow, however, the shared effects of environmental predictors and elevation were more important (Fig. 3b). In addition, the unexplained variance in the forest was higher than that in the meadow.

\section{Discussion}

\subsection{Broken elevational diversity patterns and unmodified biomass patterns at treeline}

Consistent with a recent pioneer study focusing on beetle assemblages (Werenkraut and Ruggiero, 2014), the disparity in elevational diversity patterns observed below- and above-treeline (Fig. 1a,b,d,e \& Table 3) is likely caused by sharp habitat discontinuities (forest versus meadow) at the treeline. The striking replacement of vegetation types and functional groups aboveground not only alter the resource input to belowground (Wardle et al., 2004a), but also change the habitat and distribution of soil invertebrates (Nielsen et al., 2010). In contrast to our expectations, the elevational patterns of biomass were not modified at the treeline (Fig. 1c,f \& Table 3) like diversity, which indicated that the production of soil fauna may respond less dramatically than expected to the strong vegetation changes ongoing aboveground. One possible reason is that higher omnivory and more trophic levels existing in soil food webs (Digel et al., 2014) may buffer the impacts of discontinuous changes in resources for soil invertebrates. We suggest any efforts aimed at providing a unifying theory for response of community attributes to environmental change should integrate both diversity and biomass.

Compared with meadows, forests are characterized by a higher 

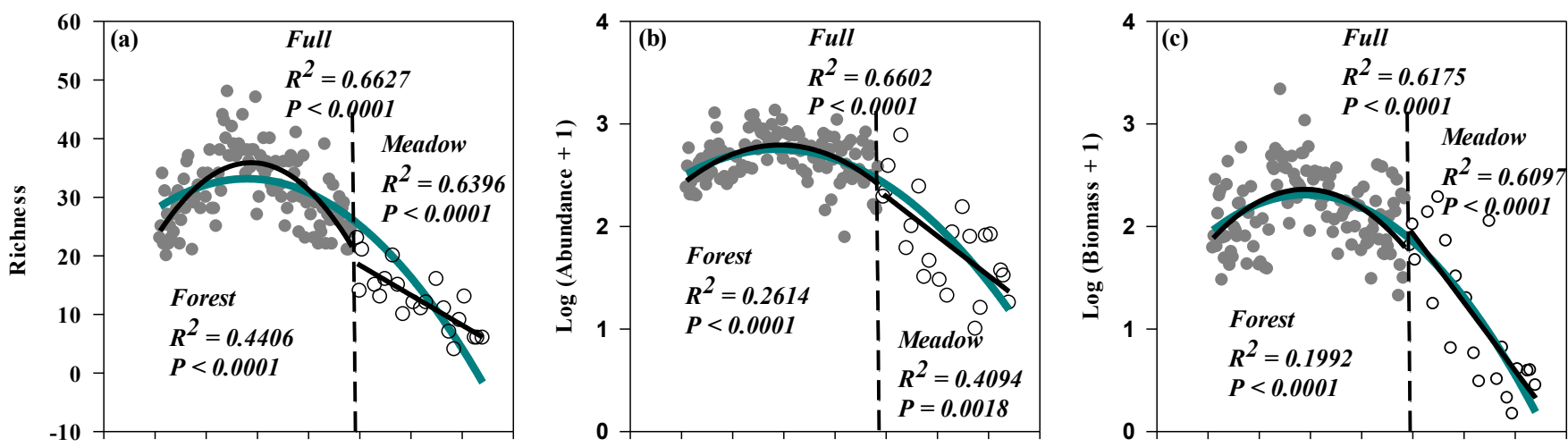

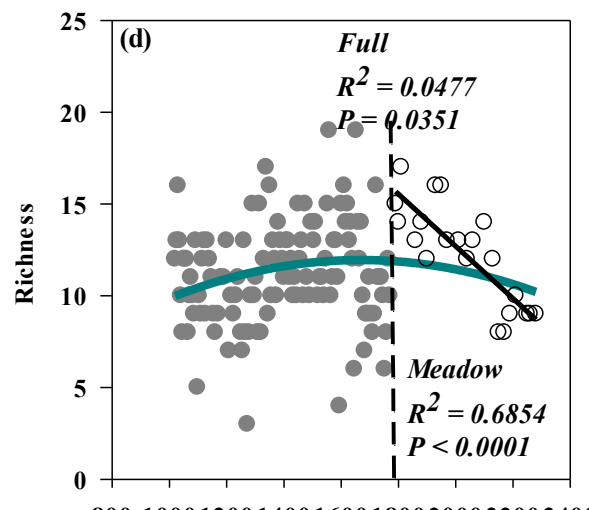

80010001200140016001800200022002400

Elevation (m)

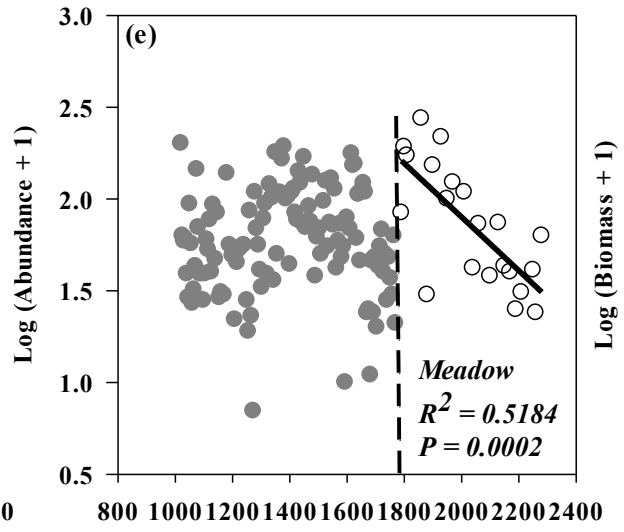

Elevation (m)

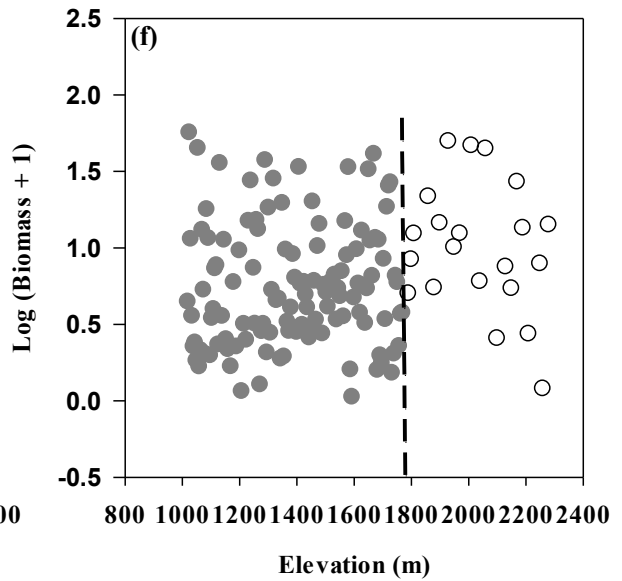

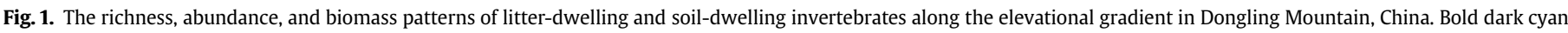

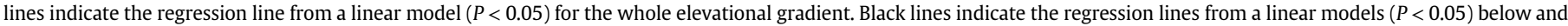

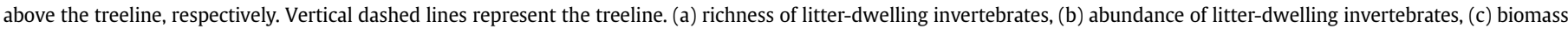

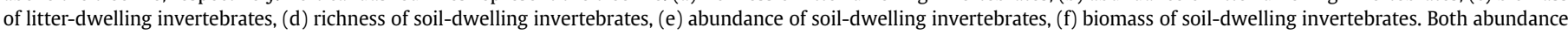

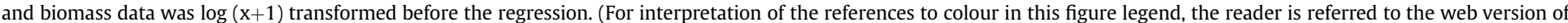
this article.)

Table 2

Interactive effects of elevation and vegetation on the richness, abundance, and biomass of soil invertebrates based on GLM analysis.

\begin{tabular}{llll}
\hline Response variable & Effect & F value $(1,136)$ & $p$ value \\
\hline LDIRICH & Ele & 11.16 & $\mathbf{0 . 0 0 1 1}$ \\
& Ele*Veg & 7.10 & $\mathbf{0 . 0 0 8 7}$ \\
SDIRICH & Veg & 2.94 & 0.0885 \\
& Ele & 11.35 & $\mathbf{0 . 0 0 1}$ \\
& Ele*Veg & 16.50 & $<\mathbf{0 . 0 0 0 1}$ \\
LDIABUN & Veg & 17.27 & $<\mathbf{0 . 0 0 0 1}$ \\
& Ele & 28.32 & $<\mathbf{0 . 0 0 0 1}$ \\
& Ele*Veg & 26.73 & $<\mathbf{0 . 0 0 0 1}$ \\
SDIABUN & Veg & 17.40 & $<\mathbf{0 . 0 0 0 1}$ \\
& Ele & 13.60 & $\mathbf{0 . 0 0 0 3}$ \\
& Ele*Veg & 13.84 & $\mathbf{0 . 0 0 0 3}$ \\
LDIBIO & Veg & 15.08 & $\mathbf{0 . 0 0 0 2}$ \\
& Ele & 38.48 & $<\mathbf{0 . 0 0 0 1}$ \\
& Ele*Veg & 34.44 & $<\mathbf{0 . 0 0 0 1}$ \\
SDIBIO & Veg & 25.97 & $<\mathbf{0 . 0 0 0 1}$ \\
& Ele & 1.01 & 0.3173 \\
& Ele*Veg & 1.63 & 0.2036 \\
& Veg & 2.17 & 0.1433 \\
\hline
\end{tabular}

LDIRICH $=$ litter-dwelling invertebrates richness, SDIRICH $=$ soil-dwelling invertebrates richness, LDIABUN = litter-dwelling invertebrates abundance, SDIABUN = soil-dwelling invertebrates abundance, LDIBIO = litter-dwelling invertebrates biomass, SDIBIO $=$ soil-dwelling invertebrates biomass. Significant $p$ values ( $p$ value $<0.05$ ) are shown in bold.

architectural complexity with distinct layers (Scherber et al., 2014) and higher primary productivity. The absence of a clear elevational
Table 3

Residuals compassion on the model fitting of the soil invertebrates' elevational diversity and biomass patterns across the whole gradient and two separate gradients below and above the treeline based on the pair-sampled $\mathrm{T}$ test.

\begin{tabular}{llll}
\hline Response variable & $\mathrm{t}$ & $\mathrm{Df}$ & $p$ value \\
\hline LDIRICH & 4.0919 & 139 & $<\mathbf{0 . 0 0 0 1}$ \\
SDIRICH & 3.1652 & 139 & $\mathbf{0 . 0 0 1 9}$ \\
LDIABUN & 2.0222 & 139 & $\mathbf{0 . 0 4 5 1}$ \\
SDIABUN & 2.7084 & 139 & $\mathbf{0 . 0 0 7 6}$ \\
LDIBIO & 1.6429 & 139 & 0.1027 \\
SDIBIO & 0.9336 & 139 & 0.3521 \\
\hline
\end{tabular}

Abbreviations are the same as Table 2. Significant $p$ values ( $p$ value $<0.05$ ) are shown in bold.

pattern for soil-dwelling invertebrates may be due to the more complex root architecture in forest (Jackson et al., 1996). First, the spatial heterogeneity (da Silva et al., 2015) perceived by soildwelling invertebrates, which differs from that of litter-dwelling invertebrates, may obscure any inter-site differences in diversity levels across the elevational gradient. Second, resource availability (humus form) and microclimate (temperature and moisture levels), displayed by the distinct microhabitat, are more stable for invertebrates inhabiting soil layers than those of litter layers (Heiniger et al., 2015). Another possible reason is that soil-dwelling invertebrates may correlate with the dominant trees, in a manner similar to fungal and bacterial communities (Urbanová et al., 2015). 
Table 4

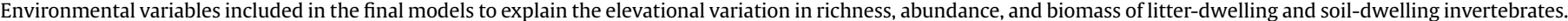

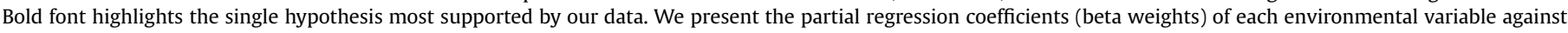
richness, abundance, and biomass. The quadratic items are shown in italics.

\begin{tabular}{|c|c|c|c|c|}
\hline Vegetation & Response variable & $\mathrm{R}^{2}$ & Hypotheses involved & More important variables (beta weights) \\
\hline \multirow[t]{6}{*}{ FOREST } & LDIRICH & 0.533 & $\begin{array}{l}\text { Productivity/ } \\
\text { Heterogeneity/Soils } 1\end{array}$ & $\begin{array}{l}\text { LITTERTH(0.421), BASEA(0.226), } \\
\text { HERBRICH }(-0.207), T_{S R I C H}^{2}(-0.167), \text { BULKDEN }(0.216)\end{array}$ \\
\hline & SDIRICH & 0.172 & $\begin{array}{l}\text { Soils 2/ } \\
\text { Soils } 1\end{array}$ & $\begin{array}{l}\mathbf{p H}(\mathbf{0 . 2 9 8}), \mathbf{A P}(\mathbf{0 . 2 1 9}) \\
\text { SAND }(0.227)\end{array}$ \\
\hline & LDIABUN & 0.289 & $\begin{array}{l}\text { Productivity/ } \\
\text { Heterogeneity/Microclimate }\end{array}$ & $\begin{array}{l}\text { BASEA(0.271), LITTERTH(0.154), } \\
T S R I C H^{2}(-0.213), \text { MAT }(-0.186)\end{array}$ \\
\hline & SDIABUN & 0.245 & $\begin{array}{l}\text { Soils 1/ } \\
\text { Heterogeneity/Soils } 2\end{array}$ & $\begin{array}{l}\text { SAND(0.372), } \\
\text { HERBRICH(-0.22), TP (0.178) }\end{array}$ \\
\hline & LDIBIO & 0.458 & $\begin{array}{l}\text { Soils 1/ } \\
\text { Productivity/Soils } 2\end{array}$ & $\begin{array}{l}\text { BULKDEN(0.309), SAND(0.292), MOISTURE(0.249), } \\
\text { LITTERTH (0.278), BASEA (0.179), N (-0.189) }\end{array}$ \\
\hline & SDIBIO & 0.131 & $\begin{array}{l}\text { Soils 1/ } \\
\text { Microclimate/Heterogeneity }\end{array}$ & $\begin{array}{l}\text { MOISTURE(0.297), SAND(-0.211), } \\
\text { TVAR(-0.2), HERBRICH }{ }^{2}(-0.179)\end{array}$ \\
\hline \multirow[t]{6}{*}{ MEADOW } & LDIRICH & 0.781 & $\begin{array}{l}\text { Microclimate/ } \\
\text { Heterogeneity }\end{array}$ & $\begin{array}{l}\text { TINS(0.616), } \\
\text { HERBRICH }(0.414)\end{array}$ \\
\hline & SDIRICH & 0.845 & $\begin{array}{l}\text { Microclimate/ } \\
\text { Heterogeneity }\end{array}$ & $\begin{array}{l}\text { TINS(0.413), } \\
\text { HERBRICH(0.392) }\end{array}$ \\
\hline & LDIABUN & 0.601 & $\begin{array}{l}\text { Microclimate/ } \\
\text { Soils } 2\end{array}$ & $\begin{array}{l}\text { TINS(0.836), } \\
\mathrm{pH}(-0.381)\end{array}$ \\
\hline & SDIABUN & 0.673 & $\begin{array}{l}\text { Soils 2/ } \\
\text { Soils } 1\end{array}$ & $\begin{array}{l}\text { TP(-0.529), } \\
\text { SILT }(0.384)\end{array}$ \\
\hline & LDIBIO & 0.615 & Microclimate & TINS(0.757) \\
\hline & SDIBIO & 0.467 & $\begin{array}{l}\text { Soils } 1 / \\
\text { Soils } 2\end{array}$ & $\begin{array}{l}\text { BULKDEN(0.453), } \\
\text { AP }(0.43)\end{array}$ \\
\hline
\end{tabular}

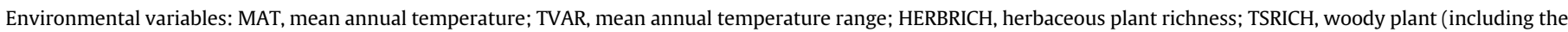

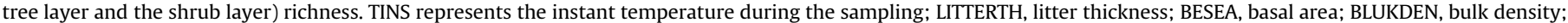
$\mathrm{TP}$, total phosphorous content; AP, available phosphorous content.
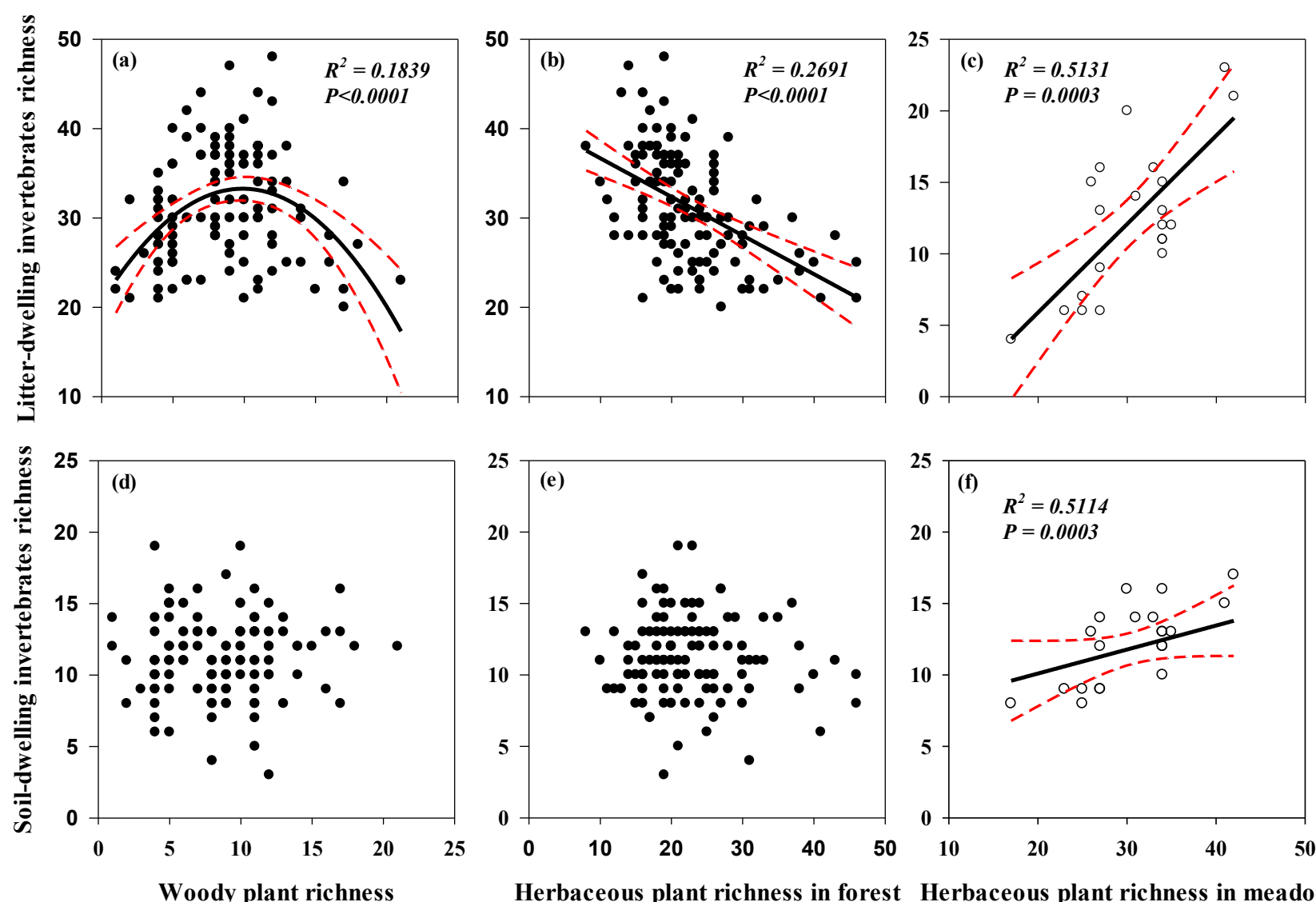

Herbaceous plant richness in forest Herbaceous plant richness in meadow

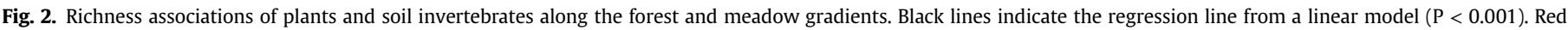

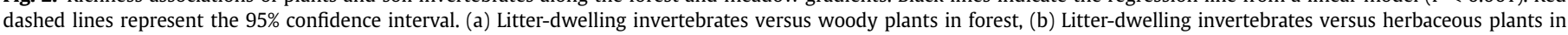

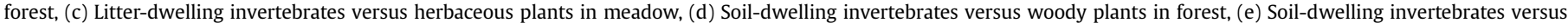

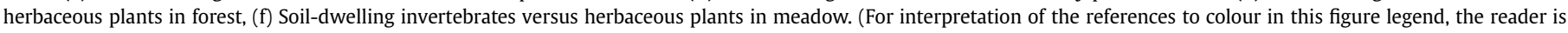
referred to the web version of this article.) 

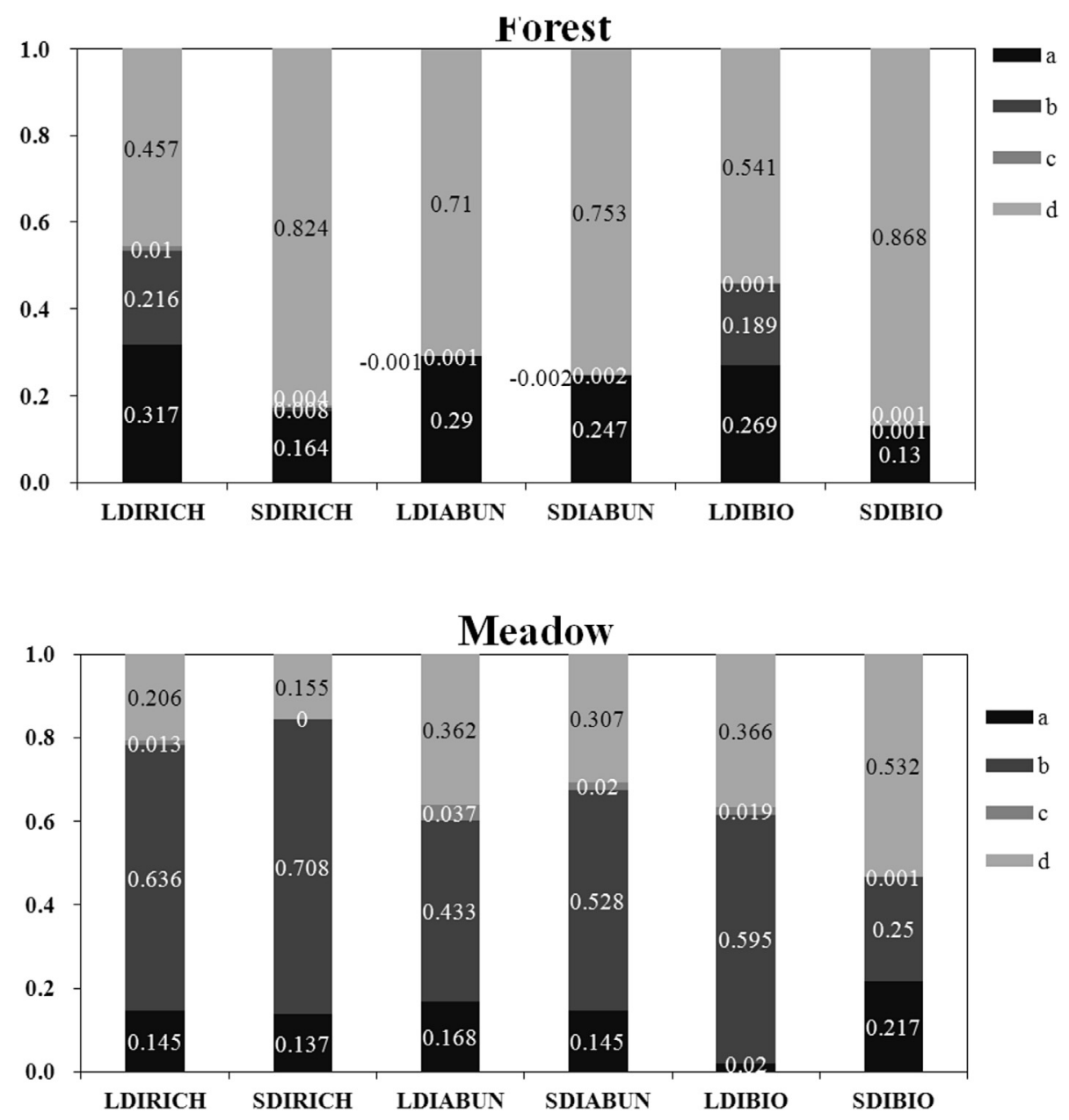

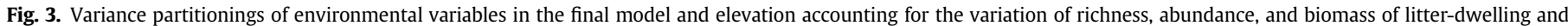

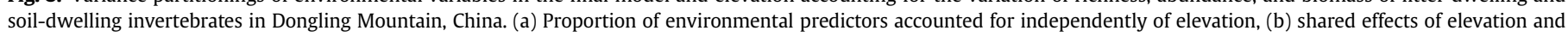
environmental predictors, (c) spatial variation accounted for by elevation, independently of environmental variables, and (d) unexplained variation.

\subsection{Dominant environmental variables driving the soil invertebrate shift at treeline}

Considering the direct effects of environmental temperature on thermoregulation, activity and development rates of ectotherms (Kingsolver, 1989), the diversity of soil invertebrates can be predicted by temperature in meadows, as supported in further analysis on the relationships of diversity and explanatory variable (temperature) contained in the best model (positively linear correlated showed in Fig. S2 in Appendix S3) in our study. More fundamental concepts such as metabolic theory may, thus, apply to soil organisms as well as to plants (Stegen et al., 2009). Declining temperature may also reduce net nutrient mineralization and nitrification rates with increasing elevation (Sveinbjornsson et al., 1995) as well as control microbial activity (Schimel et al., 2004), indirectly affecting soil invertebrates. However, the response to temperature changes could be offset or reversed by vegetation shifts (Sundqvist et al., 2011). Compared to meadows with no protection from microclimate variations by a woody canopy, forest ecosystems display more stable environmental conditions in the understory (Heiniger et al., 2015), conditions under which soil invertebrates might respond less to temperature. Another possible reason could also be nonlinear effects of microclimate so that a small change makes a larger impact at higher elevation.

Productivity represents the total amount of available energy (such as food resources), which are pivotal for the maintenance of population size (Evans et al., 2005). We demonstrated that plant productivity was more important than resource heterogeneity (represented by plant diversity) in shaping richness and abundance of soil invertebrates, which is consistent with relevant studies on insects (Woodcock and Pywell, 2010; Beck et al., 2017). Litterdwelling invertebrates are positively correlated with productivity (represented by litter thickness and base area, also see in Fig. S3 in Appendix S3), which demonstrates that more productive sites harbor higher diversity (Scherber et al., 2014) and biomass (Table 4) for decomposer communities. Despite little evidence supported resource heterogeneity as the dominant mechanism for litter- or soil-dwelling invertebrates in forest or meadow, it was indeed included in most of the final models (Table 4). This result confirms the secondary importance of resource heterogeneity in explaining richness distribution patterns (Field et al., 2009).

\subsection{Richness associations of the soil invertebrates and plants are context dependent}

Contrary to our expectations, the richness of litter-dwelling invertebrates in forest showed a hump-shaped relationship with woody species richness in forest (Fig. 2a). This may be explained under the framework of the "multivariate productivity-diversity (MPD) hypothesis", which was initially proposed to unify a better 
understanding of the multiple drivers and outcomes of productivity and diversity focusing on autotrophs (Cardinale et al., 2009). A more ready supply of available resource types (litter heterogeneity) often leads to more diverse decomposers. At the same time, more diverse plants result in greater competitive stress for decomposers (Eisenhauer et al., 2009), which may reduce the diversity of decomposers by competitive exclusion. The relationships between soil invertebrates and herbaceous plant richness (negatively correlated in forest and positively in meadow, Fig. 2b,c,f) can be explained under the framework of the "stress gradient hypothesis (SGH)", which postulates that positive interactions predominate under stressful environmental conditions (such as in meadows, Fig. 2c,f) and that negative interactions prevail under benign conditions (such as in forests, Fig. 2b) (Maestre et al., 2009). The negative relationships between richness of litter-dwelling invertebrates and herbs may also arise from the effects of other environmental variables not included in the present study. For example, light conditions in forests may affect herbaceous plants and litter-dwelling invertebrates in contrasting ways, as the understory species are negatively affected by shading (White et al., 1999) from the overstory, under which litter-dwelling invertebrates may benefit.

The hypotheses discussed above do not exclude other possible mechanisms that may drive the elevational patterns in soil invertebrates. For instance, the mid-domain effect (MDE) may also account for the spatial distribution of soil biota (Wang et al., 2011). One drawback we must notify is taxonomic resolution, considering that soil invertebrates were only classified into family or morphospecies. However, previous studies showed that the family level may be sufficient when considering the relationship between soil invertebrates and habitat preference (Doblas-Miranda et al., 2008; Ponge and Salmon, 2013). This can also be seen as a systematic error, as we classify all samples and do all analysis at the same taxonomic resolution. Future studies should utilize data with higher resolution taxonomic information and integrate it with more hypotheses to examine the underlying mechanisms driving the elevational patterns for a range of interacting communities across all trophic levels.

\section{Conclusion}

We showed that there were breaks in elevational diversity patterns of soil invertebrates at the treeline, while elevational patterns of biomass were not modified. Microclimate replaced productivity as the main factor driving the diversity patterns of litter-dwelling invertebrates across the treeline. Although the best explanatory variables shifted at treeline, the secondary important environmental correlates were resource heterogeneity both below and above the treeline. Our results indicate that soil invertebrate community mainly response to resource availability below treeline versus that of abiotic environmental filter (eg. temperature) above treeline.

\section{Statement of authorship}

GRX, KMM, SZ, YXZ and YHL designed the experiment. GRX and SZ did the field investigation of soil invertebrates. YXZ and GXL did the plant investigation. GRX identified the invertebrates and measured soil physical characteristics in lab, while GXL measured soil chemical characteristics. Statistical procedures were performed by GRX and SZ. GRX wrote the first draft of the manuscript. All authors contributed substantially to the manuscript.

\section{Acknowledgments}

This study was supported by National Natural Science Foundation of China (31470481). We would like to thank Yanpeng Xu and Ping Lu for help of the identification of soil invertebrates. We also thank Quan Chen, Qiang Zhang, Zihan Jiang, and Bingbing Wang for help of the field sampling of soil invertebrates. We thank four anonymous reviewers as well as the editor for their valuable comments that have improved this article substantially.

\section{Appendix A. Supplementary data}

Supplementary data related to this article can be found at http:// dx.doi.org/10.1016/j.soilbio.2017.05.012.

\section{References}

Bardgett, R.D., van der Putten, W.H., 2014. Belowground biodiversity and ecosystem functioning. Nature 515, 505-511.

Beck, J., Mccain, C.M., Axmacher, J.C., Ashton, L.A., Bärtschi, F., Brehm, G., Choi, S.W., Cizek, O., Colwell, R.K., Fiedler, K., 2017. Elevational species richness gradients in a hyperdiverse insect taxon: a global meta-study on geometrid moths. Global Ecology and Biogeography 26, 412-424.

Burnham, K.P., Anderson, D.R., 2002. Model Selection and Multimodel Inference. A Practical Information-theoretic Approach, second ed. Springer-Verlag, New York.

Cardinale, B.J., Bennett, D.M., Nelson, C.E., Gross, K., 2009. Does productivity drive diversity or vice versa? A test of the multivariate productivity-diversity hypothesis in streams. Ecology 90, 1227-1241.

Chen, L., Huang, J., 1997. Forest ecosystem Structure and Function in a Typical Warm Temperate Zone. Science Press, Beijing.

Collins, N.M., 1980. Distribution of soil macrofauna on the west ridge of Gunung (Mount) Mulu, Sarawak. Oecologia 44, 263-275.

da Silva, M.P., Berg, M., da Silva, A.A., Dias, S., Leitão, P., Chamberlain, D., Niemelä, J., Serrano, A.M., Sousa, J., 2015. Soil fauna through the landscape window: factors shaping surface-and soil-dwelling communities across spatial scales in corkoak mosaics. Landscape Ecology 30, 1511-1526.

Dawes, M.A., Philipson, C.D., Fonti, P., Bebi, P., Hattenschwiler, S., Hagedorn, F., Rixen, C., 2015. Soil warming and $\mathrm{CO}_{2}$ enrichment induce biomass shifts in alpine tree line vegetation. Global Change Biology 21, 2005-2021.

Decaëns, T., 2010. Macroecological patterns in soil communities. Global Ecology and Biogeography 19, 287-302.

Digel, C., Curtsdotter, A., Riede, J., Klarner, B., Brose, U., 2014. Unravelling the complex structure of forest soil food webs: higher omnivory and more trophic levels. Oikos 123, 1157-1172.

Doblas-Miranda, E., Wardle, D.A., Peltzer, D.A., Yeates, G.W., 2008. Changes in the community structure and diversity of soil invertebrates across the Franz Josef Glacier chronosequence. Soil Biology and Biochemistry 40, 1069-1081.

Eisenhauer, N., Milcu, A., Nitschke, N., Sabais, A.C.W., Scherber, C., Scheu, S., 2009. Earthworm and belowground competition effects on plant productivity in a plant diversity gradient. Oecologia 161, 291-301.

Evans, K.L., Warren, P.H., Gaston, K.J., 2005. Species-energy relationships at the macroecological scale: a review of the mechanisms. Biological Reviews 80, $1-25$.

Field, R., Hawkins, B.A., Cornell, H.V., Currie, D.J., Diniz-Filho, J.A.F., Guegan, J.F., Kaufman, D.M., Kerr, J.T., Mittelbach, G.G., Oberdorff, T., O'Brien, E.M., Turner, J.R.G., 2009. Spatial species-richness gradients across scales: a metaanalysis. Journal of Biogeography 36, 132-147.

Flombaum, P., Sala, O.E., 2007. A non-destructive and rapid method to estimate biomass and aboveground net primary production in arid environments. Journal of Arid Environments 69, 352-358.

Gonzalez, G., Garcia, E., Cruz, V., Borges, S., Zalamea, M., Rivera, M.M., 2007. Earthworm communities along an elevation gradient in Northeastern Puerto Rico. European Journal of Soil Biology 43, S24-S32.

Grytnes, J.A., Mccain, C.M., 2007. Elevational trends in biodiversity. Encyclopedia of Biodiversity 1-8.

Heiniger, C., Barot, S., Ponge, J.-F., Salmon, S., Meriguet, J., Carmignac, D., Suillerot, M., Dubs, F., 2015. Collembolan preferences for soil and microclimate in forest and pasture communities. Soil Biology and Biochemistry 86, 181-192.

Hoch, G., Korner, C., 2012. Global patterns of mobile carbon stores in trees at the high-elevation tree line. Global Ecology and Biogeography 21, 861-871.

Hurlbert, A.H., Stegen, J.C., 2014. When should species richness be energy limited, and how would we know? Ecology Letters 17, 401-413.

Jackson, R.B., Canadell, J., Ehleringer, J.R., Mooney, H.A., Sala, O.E., Schulze, E.D., 1996 A global analysis of root distributions for terrestrial biomes. Oecologia 108, 389-411.

Jiang, H., Huang, J., Chen, L., Yang, C., Yang, X., 1994. DCA ordination, quantitative classification and environmental interpretation of plant communities in Dongling Mountain. Acta Botanica Sinica 36, 539-539.

Kingsolver, J.G., 1989. Weather and the population-dynamics of insects - integrating 
physiological and population ecology. Physiological Zoology 62, 314-334.

Loranger, G., Bandyopadhyaya, I., Razaka, B., Ponge, J.F., 2001. Does soil acidity explain altitudinal sequences in collembolan communities? Soil Biology and Biochemistry 33, 381-393.

Maestre, F.T., Callaway, R.M., Valladares, F., Lortie, C.J., 2009. Refining the stressgradient hypothesis for competition and facilitation in plant communities. Journal of Ecology 97, 199-205.

Nielsen, U.N., Osler, G.H.R., Campbell, C.D., Burslem, D., van der Wal, R., 2010. The influence of vegetation type, soil properties and precipitation on the composition of soil mite and microbial communities at the landscape scale. Journal of Biogeography 37, 1317-1328.

Nielsen, U.N., Osler, G.H.R., van der Wal, R., Campbell, C.D., Burslem, D., 2008. Soil pore volume and the abundance of soil mites in two contrasting habitats. Soil Biology and Biochemistry 40, 1538-1541.

Nogues-Bravo, D., Araujo, M.B., Romdal, T., Rahbek, C., 2008. Scale effects and human impact on the elevational species richness gradients. Nature 453, 216-219.

Ponge, J.F., Salmon, S., 2013. Spatial and taxonomic correlates of species and species trait assemblages in soil invertebrate communities. Pedobiologia 56, 129-136.

Rahbek, C., 2005. The role of spatial scale and the perception of large-scale speciesrichness patterns. Ecology Letters 8, 224-239.

Rangel, T.F., Diniz-Filho, J.A.F., Bini, L.M., 2010. SAM: a comprehensive application for spatial analysis in macroecology. Ecography 33, 46-50.

Scherber, C., Vockenhuber, E., Stark, A., Meyer, H., Tscharntke, T., 2014. Effects of tree and herb biodiversity on Diptera, a hyperdiverse insect order. Oecologia 174, 1387-1400.

Schimel, J.P., Bilbrough, C., Welker, J.A., 2004. Increased snow depth affects microbial activity and nitrogen mineralization in two Arctic tundra communities. Soil Biology and Biochemistry 36, 217-227.

Stegen, J.C., Enquist, B.J., Ferriere, R., 2009. Advancing the metabolic theory of biodiversity. Ecology Letters 12, 1001-1015.

Sundqvist, M.K., Giesler, R., Graae, B.J., Wallander, H., Fogelberg, E., Wardle, D.A., 2011. Interactive effects of vegetation type and elevation on aboveground and belowground properties in a subarctic tundra. Oikos 120, 128-142.
Sveinbjornsson, B., Davis, J., Abadie, W., Butler, A., 1995. Soil carbon rind nitrogen mineralization at different elevations in the Chugach mountains of SouthCentral Alaska, USA. Arctic and Alpine Research 27, 29-37.

Urbanová, M., Šnajdr, J., Baldrian, P., 2015. Composition of fungal and bacteria communities in forest litter and soil is largely determined by dominant trees. Soil Biology and Biochemistry 84, 53-64.

von Humboldt, A., 1849. Aspects of Nature, in Different Lands and Different Climates; with Scientific Elucidations, vol. II (Transl. EJ Sabine. Longman, Brown, Green, Longmans, John Murray, London).

Wall, D.H., Nielsen, U.N., Six, J., 2015. Soil biodiversity and human health. Nature $528,69-76$

Wallwork, J.A., 1976. The Distribution and Diversity of Soil Fauna. Academic Press, New York.

Wang, J., Soininen, J., Zhang, Y., Wang, B., Yang, X., Shen, J., 2011. Contrasting patterns in elevational diversity between microorganisms and macroorganisms. Journal of Biogeography 38, 595-603.

Wardle, D.A., Bardgett, R.D., Klironomos, J.N., Setala, H., van der Putten, W.H., Wall, D.H., 2004a. Ecological linkages between aboveground and belowground biota. Science 304, 1629-1633.

Wardle, D.A., Walker, L.R., Bardgett, R.D., 2004b. Ecosystem properties and forest decline in contrasting long-term chronosequences. Science 305, 509-513.

Werenkraut, V., Ruggiero, A., 2014. The richness and abundance of epigaeic mountain beetles in north-western Patagonia, Argentina: assessment of patterns and environmental correlates. Journal of Biogeography 41, 561-573.

White, A.S., Witham, J.W., Hunter, M.L., Kimball, A.J., 1999. Relationship between plant species richness and biomass in a coastal Maine Quercus-Pinus forest. Journal of Vegetation Science 10, 755-762.

Woodcock, B.A., Pywell, R.F., 2010. Effects of vegetation structure and floristic diversity on detritivore, herbivore and predatory invertebrates within calcareous grasslands. Biodiversity and Conservation 19, 81-95.

Xu, G., Zhang, S., Lin, Y., Ma, K., 2015. Context dependency of the density-body mass relationship in litter invertebrates along an elevational gradient. Soil Biology and Biochemistry 88, 323-332. 